\title{
Nausea-inducing illness caused by cannabis still underdiagnosed
}

\author{
Cite as: CMAJ 2019 November 25;191:E1316-7. doi: 10.1503/cmaj.1095820
}

Posted on cmajnews.com on November 6, 2019.

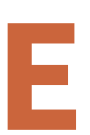
mergency doctors in the Greater Toronto Area say cannabinoid hyperemesis syndrome (CHS) is underdiagnosed and there isn't enough public awareness of the condition.

Dr. Lloyd Gordon, an emergency physician at Humber River Hospital, says he often sees one patient a shift with the condition. "You look at their history and they've had ultrasounds, [CT] scans, and nowhere does it say that the patient was advised to stop smoking marijuana," he says. "It's frustrating because the public is completely unaware of it, and that includes the people who are smoking marijuana. Their parents, especially, have no idea."

Making matters worse, Gordon says, physicians are reluctant to diagnose CHS because "a lot of doctors have trouble believing in something unless they can do a test."

Dr. Val Ginzburg, who works at Oak Ridges Endoscopy Centre as well as at emergency departments in the Toronto area, agrees that the condition is often missed. "I have patients come to me after a multiple number of [gastrointestinal] and emerg visits, multiple gastroscopies, multiple investigations, and I explain to them what's happening and it's a revelation. It's the first they've heard of it."

The mechanism of cannabinoid hyperemesis syndrome is poorly understood but its symptoms are well documented. People with CHS have episodes of abdominal pain and vomiting that can occur 20 times or more, and can last a day or two, according to a 2015 article in CMAJ.

Another tell-tale sign is that medications don't help. Ginzburg first noticed patients with mysterious vomiting in the early 2000s. "We gave them fluids, we gave them antiemetics, nothing worked," he said. After CHS made it into the medical literature in 2004, he started asking patients about cannabis use and noticed a pattern.

One popular theory is that overstimulation of the cannabinoid receptors, which are involved in the regulation of nausea, cause them to malfunction. According to the Rome IV criteria to diagnose CHS, a patient must have episodic vomiting resembling cyclic vomiting syndrome after prolonged, excessive cannabis use, with relief coming only after sustained cessation of cannabis.
Dr. Atul Kapur, cochair of the public affairs committee of the Canadian Association of Emergency Physicians, says he's surprised to hear concerns about underdiagnosis. "In the last two to three years, it's become fairly common knowledge that this entity exists and that it's worth checking in the history and advising the patients to try abstinence," he says. In his experience talking with colleagues, "an urban emergency department is seeing this at least a couple of times a week."

Dr. Michael Verbora, chief medical officer of the medical cannabis company Aleafia Health, sees far less instances of CHS. He has prescribed medical cannabis to

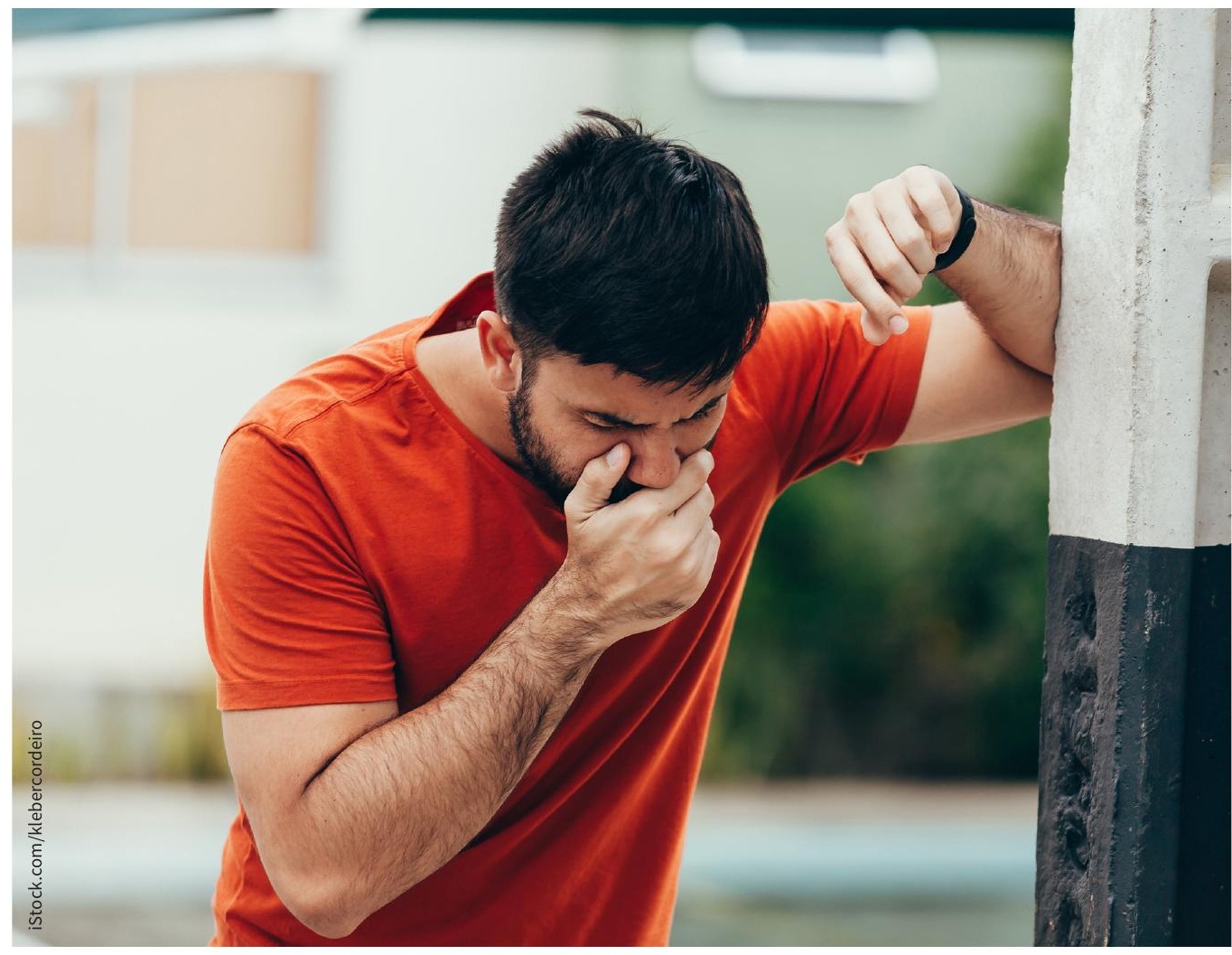

Cannabinoid hyperemesis syndrome causes abdominal pain and repeated vomiting. 
about 5000 patients and has diagnosed only two with the condition. He says high concentrations of tetrahydrocannabinol (THC) is the likely culprit but there's not enough evidence to rule out other possible causes, like a pesticide in the cannabis.

Convincing patients of the disorder isn't easy. "Some people refuse to accept that it could be the cannabis. They are convinced that it's only therapeutic and there are no harms with it. I tell them, 'Look, I prescribe cannabis for a living, so if anybody's going to be upfront about it, it's me," says Verbora. In cases where doctors aren't sure of the diagnosis, and patients are resistant to abstaining, he suggests that as a harm reduction strategy, patients be encouraged to try a cannabidiol oil with little or no THC.

Verbora thinks some doctors aren't adequately aware of CHS but worries others could be too quick to jump to the diagnosis. "We have to be careful because cannabis is stigmatized, so it's very easy, if somebody who uses cannabis comes in, to make a quick judgement, based on our own biases," he says. He recommends doctors stick to the Rome IV criteria for diagnosis, and also ask about hot showers.

Many patients who visit emergency departments have already been using hot showers for relief, report Gordon and Ginzburg. "You ask the parent, 'Is he living in the shower?' And they'll say, 'Oh yeah, for the last few days,'” says Gordon.

While Ginzburg understands doctors don't want to miss anything serious, he says doctors should feel comfortable making the diagnosis if the criteria are met, without ordering other tests. "There are conditions in medicine, such as migraine headache, where we diagnose the condition based on the presentation patterns, without further investigation."

Wendy Glauser, Toronto, Ont. 